\title{
Limited health literacy is associated with poorer clinical outcomes in elderly with type 2 diabetes mellitus
}

\author{
Gulay Yilmazel*@a and Remziye Cici**
}

\begin{tabular}{l} 
ABSTRACT \\
\hline BACKGROUND \\
Diabetes mellitus is a significant global public health concern. Poor \\
knowledge of disease and healthcare utilization is associated with poor \\
health outcomes, leading to increasing burden of diabetes in many \\
developing countries. The present study aimed to assess diabetes health \\
literacy and clinical outcomes in elderly patients registered to the home \\
health agency.
\end{tabular}

\section{METHODS}

A cross-sectional study was conducted in the city of Çorum, Turkey, with 160 type 2 diabetic patients of both sexes and aged between 50-91 years. To identify health literacy, the Rapid Estimate of Adult Literacy in Medicine test was administered to the patients. Clinical parameters were based on routine medical examinations by measuring blood pressure levels, glycosylated hemoglobin, and lipoprotein levels. In order to identify the risk of depression, the Beck Depression Scale was used.

\section{RESULTS}

Of the patients, $85.0 \%$ had limited health literacy. The majority of patients $(95.0 \%)$ had poor glycemic control and limited health literacy was associated with having high level of HbAlc $(\mathrm{p}<0.05)$. Adequate health literacy was associated with regular foot care $(\mathrm{p}<0.05)$. Also patients with limited health literacy were more likely to have depression $(\mathrm{p}<0.001)$. Limited health literacy increased the risk of poor glycemic control $(\mathrm{OR}=6.82 ; 95 \% \mathrm{CI}=1.34-9.78)$ and retinopathy $(\mathrm{OR}=6.91 ; 95 \% \mathrm{CI}=1.23-9.44)$.

\section{CONCLUSION}

Limited health literacy is consistently associated with poorer diabetes clinical outcomes in elderly type 2 diabetes melltius Contents of diabetes education should be arranged according to patients' health literacy level which requires visual and auditory teaching materials for patients with limited health literacy.

Keywords: Health literacy; diabetes mellitus; outcomes; home health agency
*Department of Public Health, Faculty of Medicine, Hitit University, Çorum, Turkey

**Department of Nursing Faculty of Medicine, Hitit University, Corum, Turkey

\section{Correspondence}

${ }^{\circledR}$ Gulay Yilmazel, Assoc.Prof.Dr. Department of Public Health,

Hitit University Faculty of Medicine, Samsun Cd. 19000 Corum, Turkey Email: dryilmazelgul@gmail.com ORCID ID: http://orcid.org/00000002-2487-5464

Date of first submission, April 24, 2019 Date of final revised submission, November 26, 2019

Date of acceptance, November 27, 2019

This open access article is distributed under a Creative Commons AttributionNon Commercial-Share Alike 4.0 International License

Cite this article as: Gilmazel G, Cici R.
Limited health literacy is associated
with poorer clinical outcomes in eld-
erly with type 2 diabetes mellitus. Univ
Med 2019;38:179-85. doi: $10.18051 /$
UnivMed.2019.v38.179-185




\section{INTRODUCTION}

Health literacy is a broad concept that includes abilities for reading, understanding and navigating health information in the health system to make relevant appropriate decisions. ${ }^{(1)}$ Health literacy plays a vital role in self-management of chronic disease which accounts for $44 \%$ of the global burden of disease. ${ }^{(2)}$ Evidence suggests that limited health literacy is a common condition which has considerable impact on chronic conditions such as type 2 diabetes mellitus (DM), asthma, acquired immune deficiency syndrome (AIDS) and hypertension. ${ }^{(3-6)}$ According to the Global Status Report on Non-Communicable Disease, 89 million disability-adjusted life years (DALYS) was attributed to DM with estimated prevalence of $9 \%$ in 2014. (7) Patients with diabetes are at increased risk of poor health outcomes (cardiovascular disease, strokes, amputations, blindness, and end-stage renal disease) and poor control of clinical outcomes (e.g., blood pressure, lipoprotein levels, glycemic control). ${ }^{(8-10)}$ Type 2 diabetes is a classic public health problem affecting 6,503,027 Turkish people with $13.7 \%$ prevalence. ${ }^{(11)}$ In Turkey, the home health agency is a part of public health services for patients who are in a disadvantageous position due to severe illness. The population of home health care are mostly elderly. Patients with asthma, paralysis, serious respiratory insufficiency, those completely bed-ridden or physically disabled, and those with terminal cancer and severe muscle disease utilize the services in their homes. Diabetic patients with any complications can also utilize these services. Elderly individuals are one of the groups at risk of limited health literacy to implement tasks for disease control individually. ${ }^{(12,13)}$ Aging results in declined cognitive functions and therefore elderly patients feel stressful about managing diabetes tasks. Studies give an impression that elderly patients with diabetes do not appear to be receiving diabetes care at optimum level. ${ }^{(14)}$

Several studies have reported that low health literacy is related to negative health outcomes such as poor health status ${ }^{(15)}$ and inadequate disease management. ${ }^{(16)}$ Evidence examining the link between low health literacy and glycemic outcomes are mixed. Some studies have demonstrated links between higher levels of health literacy and better glycemic control, while others have failed to demonstrate an association. ${ }^{(17,18)}$ The distinguishing aspect of the present study is that participants were taking regular home care services.

The two hypotheses of this study are that patients with diabetes have limited health literacy and that these patients would be less likely to control clinical outcomes such as glycosylated hemoglobin (A1c), blood pressure and low density lipoprotein (LDL) level. The present study aimed to assess health literacy and clinical outcomes in elderly type 2 diabetic patients registered to the home health agency.

\section{METHODS}

\section{Research design}

This cross-sectional study was conducted between February-March 2019 in the city of Çorum in Turkey.

\section{Study subjects}

Patients were recruited from the home health agency. In Çorum city, 1670 patients utilize this service and 187 diabetic patients were included in the study. The calculated minimum sample size was 156 patients, based on the prevalence of DM in Turkey of $13.7 \% .^{(11)}$ Among those diabetic patients, 27 were excluded because of illiteracy, hearing impairment, psychotic disorder, dementia, blindness, aphasia, end-stage cancer and renal disease (these conditions may be a barrier to accurately measure health literacy). A total of 160 type 2 diabetic patients of both sexes and aged between 50-91 were enrolled in the study.

Patients were orally administered a questionnaire form regarding self-reported sociodemographic information (age, educational level, monthly income, marital status, self-reported 
health, smoking status, history of hypertension) and self-management behaviors (measuring blood glucose, adherence to diet and treatment, foot care). Information on diabetes condition (current treatment, complications) was collected from the patients' files.

\section{MEASUREMENTS}

\section{Health literacy}

To identify health literacy, the patients were then administered the Rapid Estimate of Adult Literacy in Medicine (REALM) test, which is a widely acknowledged test and is a practical way of measuring reading, pronunciation and comprehension of terms. It was developed by Davis et al. ${ }^{(19)}$ and converted into and validated as the Turkish version by Özdemir et al. ${ }^{(20)}$ The test scoring is based on individual responses and correct responses take "1" point. Health literacy level is structured according to total score (0$66)$ as follows: inadequate (0-44), marginal (45$60)$, adequate (61-66). In this study, health literacy was grouped in two levels as adequate and limited (marginal and inadequate) health literacy.

\section{Depression}

In order to identify the risk of depression and level of depressive symptoms, the Beck Depression Scale, including 21 self-assessment items, was used. (21) The scale was developed by Beck ${ }^{(21)}$ and validated as the Turkish version. (22) Each item takes a score between 0-3 and the total score range is $0-63$. The depression score was categorized into d"16 and e" 17 .

\section{Clinical measurements}

Following the questionnaire, systolic and diastolic blood pressure levels were measured. Then, the process of collecting clinical parameters was carried out for routine medical examinations by home health nurses. Blood samples were obtained to measure $\mathrm{HbAlc}$ and low density lipoprotein (LDL) levels. After testing, measurement values were obtained from online-laboratory systems. Poor glycemic control was defined as $\mathrm{HbA} 1 \mathrm{c}>7 \%$.

\section{Statistical analysis}

Data management and analysis were performed using SPSS 17.0. For categorical variables, Fisher's exact test was used. Multivariate logistic regression was used to predict the clinical outcomes of limited health literacy. A $p<0.05$ value was accepted as significant.

\section{Ethical approval}

The procedures of this study were performed in accordance with the Helsinki Principles and approved by the Hitit University Non-interventional Research Ethics Committee (under no. 2019-198). Informed consent was obtained from all individual participants included in the study.

\section{RESULTS}

A total of 160 elderly diabetic patients participated in this study with a mean age of 65.6 (SD:12.6) years. Of those, $47.5 \%$ were women and $52.5 \%$ were men. In the study group, $88.1 \%$ had primary education or lower. Table 1 shows patient characteristics according to health literacy level. Of the patients, $85.0 \%$ had limited (20.6\% marginal, $64.4 \%$ inadequate), and $15.0 \%$ had adequate health literacy. There were no differences in patients' gender, marital status, perceived health, smoking status, duration of diabetes, treatments, history of hypertension (HTN), LDL, blood pressure levels and macrovascular complications according to health literacy level $(\mathrm{p}>0.05)$. Limited health literacy was significantly associated with being older, having less education, and lower income $(p<0.05)$. The majority of patients $(95.0 \%)$ had poor glycemic control (HbAlc $>7$ ). Limited health literacy was associated with a high level of HbA1c $(p<0.05)$. Conversely, adequate health literacy was associated with regular foot care $(p<0.05)$. Approximately three in four patients 
Table 1. General features of the subjects by health literacy

\begin{tabular}{|c|c|c|c|c|}
\hline & $\begin{array}{c}\text { All } \\
n=160 \\
(100.0 \%)\end{array}$ & $\begin{array}{c}\text { Limited } \\
n=136 \\
(85.0 \%) \\
\end{array}$ & $\begin{array}{c}\text { Adequate } \\
\mathbf{n}=\mathbf{2 4} \\
(\mathbf{1 5 . 0} \%)\end{array}$ & $\mathbf{p}^{*}$ \\
\hline Age, mean (SD), years & $65.6(12.6)$ & $66.7(12.7)$ & $59.5(10.9)$ & 0.014 \\
\hline \multicolumn{5}{|l|}{ Sex } \\
\hline Female & $76(47.5)$ & $64(47.1)$ & $12(50.0)$ & \multirow[t]{2}{*}{0.790} \\
\hline Male & $84(52.5)$ & $72(52.9)$ & $12(50.0)$ & \\
\hline \multicolumn{4}{|l|}{ Education } & \multirow[t]{3}{*}{0.000} \\
\hline Primary and below & $141(88.1)$ & $128(94.1)$ & $13(54.2)$ & \\
\hline Secondary and over & $19(11.9)$ & $8(5.9)$ & $11(45.8)$ & \\
\hline \multicolumn{4}{|l|}{ Marital status } & \multirow[t]{3}{*}{0.156} \\
\hline Married & $114(71.3)$ & $94(69.1)$ & $20(83.3)$ & \\
\hline Not married & $46(28.8)$ & $42(30.9)$ & $4(16.7)$ & \\
\hline \multicolumn{4}{|l|}{ Income } & \multirow[t]{3}{*}{0.025} \\
\hline$\leq \$ 500$ & $32(20.0)$ & $23(16.9)$ & $9(37.5)$ & \\
\hline$>500$ & $128(80.0)$ & $113(83.1)$ & $15(62.5)$ & \\
\hline \multicolumn{4}{|l|}{ Perceived health } & \multirow[t]{4}{*}{0.576} \\
\hline Good & $28(17.5)$ & $22(16.2)$ & $6(25.0)$ & \\
\hline Moderate & $45(28.1)$ & $39(28.7)$ & $6(25.0)$ & \\
\hline Poor & $87(54.4)$ & $75(55.1)$ & $12(50.0)$ & \\
\hline \multicolumn{4}{|l|}{ Smoking status } & \multirow[t]{4}{*}{0.287} \\
\hline Current & $33(20.6)$ & 27 (19.9) & $6(25.0)$ & \\
\hline Former & $36(22.5)$ & $28(20.6)$ & $8(33.3)$ & \\
\hline None & $91(56.9)$ & $81(59.6)$ & $10(41.7)$ & \\
\hline Duration of diabetes (mean years) & $12.4(8.8)$ & $12.8(8.8)$ & $9.7(8.9)$ & 0.052 \\
\hline \multicolumn{4}{|l|}{ Treatments for diabetes } & \multirow[t]{4}{*}{0.483} \\
\hline Only oral hypoglycemic & $77(48.1)$ & $68(50.0)$ & $9(37.5)$ & \\
\hline Only insulin regimen & $37(23.1)$ & $31(22.8)$ & $6(25.0)$ & \\
\hline Insulin and oral hypoglycemic & $46(28.8)$ & $37(27.2)$ & $9(37.5)$ & \\
\hline \multicolumn{5}{|l|}{ Self-management behaviors } \\
\hline Adherence to diet & $58(36.3)$ & $51(37.5)$ & $7(29.2)$ & 0.167 \\
\hline Adherence to treatment & $104(65.0)$ & $92(67.6)$ & $12(50.0)$ & 0.059 \\
\hline Regular foot care & $94(58.8)$ & $73(53.7)$ & $21(87.5)$ & 0.008 \\
\hline Reported history of HTN & $43(26.9)$ & $38(27.9)$ & $5(20.8)$ & 0.469 \\
\hline \multicolumn{5}{|l|}{ Clinical outcomes } \\
\hline HbA1c, mean (SD) & $8.7(3.1)$ & $8.9(3.2)$ & $7.3(1.8)$ & 0.016 \\
\hline LDL cholesterol, mean (SD) & $113.3(43.4)$ & $114.1(39.8)$ & $109(61.0)$ & 0.334 \\
\hline Systolic blood pressure, mean (SD) & $126.5(19.3)$ & $126.3(20.0)$ & $127.9(15.0)$ & 0.645 \\
\hline Diastolic blood pressure, mean (SD) & $75.1(11.8)$ & $74.5(12.2)$ & $74.8(8.5)$ & 0.320 \\
\hline \multicolumn{5}{|l|}{ Microvascular complication } \\
\hline Retinopathy & $52(32.5)$ & $50(36.8)$ & $2(8.3)$ & 0.006 \\
\hline Nephropathy & $20(12.5)$ & $18(13.2)$ & $2(8.3)$ & 0.503 \\
\hline Neuropathy & $65(40.6)$ & $57(41.9)$ & $8(33.3)$ & 0.430 \\
\hline \multicolumn{5}{|l|}{ Macrovascular complication } \\
\hline Cerebrovascular disease & $47(29.4)$ & $40(29.4)$ & $7(29.2)$ & 0.981 \\
\hline Coronary artery disease & $11(6.9)$ & $10(7.4)$ & $1(4.2)$ & 0.486 \\
\hline \multicolumn{5}{|l|}{ BDS } \\
\hline Depression score $\geq 17$ & $119(74.4)$ & $119(87.5)$ & $0(0.0)$ & 0.000 \\
\hline Depression score $\leq 16$ & $41(25.6)$ & $17(12.5)$ & $24(100.0$ & \\
\hline
\end{tabular}

*Fisher's Exact test was used for categorical variables; the Kruskal-Wallis test was used for continuous variables. Abbreviations: Hypertension (HTN), Glycated hemoglobin (A1C); Low Density Lipoprotein (LDL); Beck Depression Scale (BDS)

had depression and the mean score for depression was 30.7 (SD:16.8). Patients with limited health literacy were more likely to have depression $(\mathrm{p}<0.001)$.
Table 2 shows associations between clinical outcomes and limited health literacy. Limited health literacy was 6.82 times significantly higher in patients with poor glycemic control 
Table 2. Analysis of multiple binary logistic regression between several risk factors and limited health literacy

\begin{tabular}{lccc}
\hline & \multicolumn{3}{c}{ Limited health literacy } \\
\cline { 2 - 4 } & aOR & CL & p \\
\hline Poor glycemic control (HbA1c $>7 \%)$ & 6.82 & $1.34-9.78$ & $\mathbf{0 . 0 1 7}$ \\
Retinopathy & 6.91 & $1.23-9.44$ & $\mathbf{0 . 0 1 9}$ \\
Nephropathy & 1.63 & $0.17-3.31$ & 0.576 \\
Neuropathy & 1.12 & $0.38-3.56$ & 0.820 \\
\hline aOR : adjusted OR for age and sex & &
\end{tabular}

$(\mathrm{HbA} 1 \mathrm{c}>7 \%)$ and 6.91 times significantly higher in patients with retinopathy $(\mathrm{OR}=6.82 ; 95 \%$ $\mathrm{CI}=1.34-9.78$ and $\mathrm{OR}=6.91 ; 95 \% \mathrm{CI}=1.23-9.44$, respectively) (Table 2). There was no signiûcant association between limited health literacy and other diabetes complications.

\section{DISCUSSION}

As mentioned in the reviewed literature, a chain of evidence links health literacy and diabetes care. ${ }^{(23-25)}$ This is the first study reporting the effect of limited health literacy on poor clinical outcomes in Turkish diabetic home health care patients. In the current study, the majority of diabetic patients $(85 \%)$ had limited health literacy. The results of this study are consistent with international studies. ${ }^{(26,27)}$

Socioeconomic factors (such as aging, education, income, etc.) have a dominant role in the maintenance of adequate health literacy. Prior studies have noted the problem of limited health with advanced age, less education and low income. ${ }^{(28,29)}$ The current study supports the previous studies, in that $94.1 \%$ of patients with less education and $83.1 \%$ of patients with low income had limited health literacy. These factors can contribute to high rates of poor health literacy, severe complications and poor clinical outcomes in diabetic patients.

Diabetes complications remain a major challenge despite current clinical success. Patients have to suffer from multiple complications especially foot ulcers, vision and renal problems. Maintaining relevant food hygiene and adhering to medical treatment and diet are at the heart of quality self-management of diabetes care. However, self-management behaviors in chronic disease vary depending on patients' health literacy skills. ${ }^{(30-32)}$ This study demonstrated that regular foot care was more common in patients with adequate health literacy. Glycosylated hemoglobin is an leading clinical indicator of diabetic complications. ${ }^{(33)}$ Many guidelines for diabetes recommend a target $\mathrm{HbA} 1 \mathrm{c}$ level of less than $7 \% .^{(34-36)}$ However, studies reported that diabetic patients with limited health literacy have poorer glycemic control and higher levels of retinopathy than have those with adequate health literacy level. ${ }^{(37)}$ One important and similar finding is that poor glycemic control and retinopathy was more frequent in patients with limited health literacy. Among clinical outcomes HbAlc and retinopathy had a significant correlation with limited health literacy.

Depression is an obvious accompanying psychiatric problem in patients with diabetes. ${ }^{(38,39)}$ In the present study depression was more common in diabetic patients with limited health literacy. Depression can be an aggravating circumstance for adverse outcomes which also may dash patients' hopes and restrict diabetes care.

One of the limitations of this study was that it included only home care patients. Health literacy should be seen as an important component of health education in preventing complications and sequelae in diabetic patients and low health literacy skills should not be ignored in patients receiving home care. The first step of home care services for diabetes should be to increase patients' health literacy skills. 


\section{CONCLUSIONS}

Patients with limited health literacy had poorer glycemic control and foot care, also had more retinopathy and higher depression scores. Using health literacy measurements in the home care system will be better to give a new direction and to strengthen diabetes care.

\section{CONFLICT OF INTEREST}

None

\section{ACKNOWLEDGMENTS}

The authors sincerely thank the patients of the home health agency for their participation in this study and also thank the home health agency staff for assisting with the administration of questionnaires and data collection for the study.

\section{CONTRIBUTORS}

GY designed this study. RC carried out the data analyses and reported the initial findings. GY contributed to the discussion and conclusion. Both authors have read and approved the final manuscript.

\section{REFERENCES}

1. National Center for Health Statistics Centers for Disease Control and Prevention. Healthy people 2010 final review. Hyattsville, MD; 2012.

2. World Health Organization. Global burden of disease 2000-2016. Geneva: World Health Organization;2019.

3. Lee YJ, Shin SJ, Wang RH, Lin KD, Lee YL, Wang YH. Pathways of empowerment, perceptions, health literacy, self-efficacy, and self-care behaviors to glycemic control in patients with type 2 diabetes mellitus. Patient Educ Couns 2016; 99: 287-94. doi:10.1016/j.pec.2015.08.021.

4. Cunha GH, Galvão MTG, Pinheiro PNC, Vieira NFC. Health literacy for people living with HIV/ Aids: an integrative review. Rev Bras Enferm 2017; 70:169-77. doi: 10.1590/0034-7167-2015-0052.

5. van der Heide I, Poureslami I, Mitic W, Shum J, Rootman I, FitzGerald JM. Health literacy in chronic disease management: a matter of interaction. J Clin Epidemiol 2018;102:134-8. doi: 10.1016/j.jclinepi.2018.05.010.

6. Myers L, Murray RK. Overcoming health literacy barriers to improve asthma inhaler therapy adherence. Ann Am Thorac Soc 2019;16:182-6. doi: 10.1513/AnnalsATS.201805-338PS.

7. World Health Organization. Global status report on noncommunicable diseases 2014. Geneva: World Health Organization; 2019.

8. Oscalices MIL, Okuno MFP, Lopes MCBT, Batista REA, Campanharo CRV. Health literacy and adherence to treatment of patients with heart failure. Rev Esc Enferm USP 2019;53:e03447. doi: 10.1590/S1980-220X2017039803447.

9. Bains SS, Egede LE. Associations between health literacy, diabetes knowledge, self-care behaviors, and glycemic control in a low income population with type 2 diabetes. Diabetes Tech Therapeut 2011;13:335-41.

10. Hadden K, Martin R, Prince L, Barnes CL. Patient health literacy and diabetic foot amputations. J Foot Ankle Surg 2019;58:877-9. doi: 10.1053/j.jfas. 2018.12.038.

11. Satman I, Omer B, Tutuncu Y, et al. Twelve-year trends in the prevalence and risk factors of diabetes and prediabetes in Turkish adults. Eur J Epidemiol 2013;28:169-80. doi: 10.1007/s10654013-9771-5.

12. de Almeida KMV, Toye C, Silveira LVA, Slatyer S, Hill K, Jacinto AF. Assessment of functional health literacy in Brazilian carers of older people. Dement Neuropsychol 2019;13:180-6. doi: 10.1590/198057642018dn13-020006.

13. Hochhauser M, Brusovansky M, Sirotin M, Bronfman K. Health literacy in an Israeli elderly population. Isr J Health Policy Res 2019;8:61. doi: 10.1186/s13584-019-0328-2.

14. Hu Z, Qin L, Xu H. Association between diabetesspecific health literacy and health-related quality of life among elderly individuals with pre-diabetes in rural Hunan Province, China: a cross-sectional study. BMJ Open 2019;9:e028648. doi: 10.1136/ bmjopen-2018-028648.

15. Berkman ND, Sheridan SL, Donahue KE, Halpern DJ, Crotty K. Low health literacy and health outcomes: an updated systematic review. Ann Intern Med 2011;155:97-107. doi: 10.1059/00034819-155-2-201107190-00005.

16. Bailey SC, Brega AG. Update on health literacy and diabetes. Diabetes Educ 2014;40:581-604. doi: 10.1177/0145721714540220.

17. Ishikawa H, Yano E. The relationship of patient participation and diabetes outcomes for patients with high vs. low health literacy. Patient Educ 
Counsel 2011;84:393-7. doi: 10.1016/j.pec.2011.01. 029.

18. Tang YH, Pang SM, Chan MF, Yeung GS, Yeung VT. Health literacy, complication awareness, and diabetic control in patients with type 2 diabetes mellitus. J Adv Nurs 2008;62:74-83. doi: 10.1111/j. 1365-2648.2007.04526.x.

19. Dumenci L, Matsuyama RK, Kuhn L, Perera RA, Siminoff LA. On the validity of the rapid estimate of adult literacy in medicine (REALM) scale as a measure of health literacy. Commun Methods Meas 2013;7:134 43. doi:10.1080/19312458.2013. 789839.

20. Ozdemir H, Alper Z, Uncu Y, Bilgel N. Health literacy among adults: a study from Turkey. Health Educ Res 2010;25:464-77. doi: 10.1093/her/cyp068.

21. Wang YP, Gorenstein C. Psychometric properties of the Beck Depression Inventory-II: a comprehensive review. Rev Bras Psiquiatr 2013; 35:416-31. doi:10.1590/1516-4446-2012-1048.

22. Canel-Cynarbap D, Cui Y, Lauridsen E. Crosscultural validation of the Beck Depression Inventory-II across U.S. and Turkish samples. Meas Eval Couns Develop 2011;44:77-91. https:/ /doi.org/10.1177/0748175611400289.

23. Mancuso JM. Impact of health literacy and patient trust on glycemic control in an urban USA population. Nurs Health Sci 2010;12:94-104. doi: 10.1111/j.1442-2018.2009.00506.x.

24. Ueno H, Ishikawa H, Suzuki R, et al. The association between health literacy levels and patient-reported outcomes in Japanese type 2 diabetic patients. SAGE Open Med 2019;7: 2050312119865647. doi: 10.1177/2050312119865 647.

25. Mbaezue N, Mayberry R, Gazmararian J, Quarshie A, Ivonye C, Heisler M. The impact of health literacy on self-monitoring of blood glucose in patients with diabetes receiving care in an innercity hospital. J Natl Med Assoc 2010;102:5-9. doi: 10.1016/s0027-9684(15)30469-7.

26. Sarkar U, Karter AJ, Liu JY, et al. The literacy divide: health literacy and the use of an internetbased patient portal in an integrated health system-results from the Diabetes Study of Northern California (DISTANCE). J Health Commun 2010;15 Suppl 2:183-96. doi: 10.1080/ 10810730.2010.499988.

27. Anbarasan S, Gurtoo A, Srinivasaan M, Ap MK. Level of health literacy among type 2 diabetic persons and its relation to glycemic control. J Assoc Physicians India 2019;67:59-62.
28. Verney SP, Gibbons LE, Dmitrieva NO, et al. Health literacy, sociodemographic factors, and cognitive training in the active study of older adults. Int $\mathrm{J}$ Geriatr Psychiatry 2019;34:563-70. doi: 10.1002/ gps.5051.

29. De Carvalho Sampaio HA, Carioca AAF, Sabry MOD, Dos Santos PM, Coelho MAM, Passamai MPB. Health literacy in type 2 diabetics: associated factors and glycemic control. Ciencia Saude Coletiva 2015;20:865-74. doi: 10.1590/141381232015203.12392014.

30. Taylor DM, Fraser S, Dudley C, et al. Health literacy and patient outcomes in chronic kidney disease: a systematic review. Nephrol Dial Transplant 2018; 33:1545-58. doi: 10.1093/ndt/gfx293.

31. Han HR, Song Y, Kim M, et al. Breast and cervical cancer screening literacy among Korean American women: a community health workerled intervention. Am J Public Health 2017;107:15965. 10.2105/AJPH.2016.303522.

32. Osborn CY, Bains SS, Egede LE. Health literacy, diabetes self-care, and glycemic control in adults with type 2 diabetes. Diabetes Tech Therapeut 2010;12:913-9. doi: 10.1089/dia.2010.0058.

33. Moss TR. The impact of health literacy on clinical outcomes for adults with type 2 diabetes mellitus. Advances Diabetes Metabolism 2014;2:10-9. doi: 10.13189/adm.2014.020103.

34. American Diabetes Association. Position statement, standards of medical care in diabetes2012. Diabetes Care 2012;35 Suppl1:S11-63. https:/ /doi.org/10.2337/dc12-s011.

35. Inoue K1, Matsumoto M, Akimoto K. Fasting plasma glucose and $\mathrm{HbA1c}$ as risk factors for type 2 diabetes. Diabet Med 2008;25:1157-63. doi: 10.1111/j.1464-5491.2008.02572.x.

36. Sunjaya AP, Sunjaya AF. Glycated hemoglobin targets and glycemic control: Link with lipid, uric acid and kidney profile. Diabetes Metab Syndr 2018;12:743-8. doi: 10.1016/j.dsx.2018.04.039.

37. Shrestha MK, Guo CW, Maharjan N, Gurung R, Ruit S. Health literacy of common ocular diseases in Nepal. See comment in PubMed Commons belowBMC Ophthalmol 2014;14:2. doi: 10.1186/ 1471-2415-14-2.

38. Badescu SV, Tataru C, Kobylinska L, et al. The association between diabetes mellitus and depression. J Med Life 2016;9:120-5.

39. Semenkovich K1, Brown ME, Svrakic DM, Lustman PJ. Depression in type 2 diabetes mellitus: prevalence, impact, and treatment. Drugs 2015;75:577-87. doi: 10.1007/s40265-015-0347-4. 